\title{
A formação dos psicólogos em políticas públicas: construindo uma nova realidade
}

\section{The formation of psychologists in public policies: building New reality}

\author{
Fanny Helena Martins Salles \\ Universidade da Região da Campanha
}

\begin{abstract}
Resumen
O estágio curricular de psicologia da URCAMP compreende atividades teórico-práticas referendas pelos cuidados inclusivos das políticas públicas. Oportuniza ao acadêmico uma visão crítica da realidade e o protagonismo social, bem como a emergência de novas competências. Pretende assegurar o atendimento integral aos usuários da rede de assistência à saúde, o desenvolvimento da autonomia e de ferramentas pessoais. Este relato tem origem no projeto de uma docente e quatro estagiárias, referenciado no Guia Brasileiro de gestão Autônoma de Medicação, manual criado para ser utilizado nos serviços da Rede de Atenção Psicossocial do Sistema Único de Saúde do Rio Grande do Sul.

Palavras chave: psicología, políticas públicas, inclusão,
\end{abstract}

\begin{abstract}
The URCAMP curricular psychology internship comprises theoretical-practical activities that emphasize the inclusive care of public policies. It offers the academic a critical view of reality and social protagonism, as well as the emergence of new skills. It aims to ensure the integral care to users of the health care network, the development of autonomy and personal tools. This report originates in the project of one teacher and four trainees and referenced in the Brazilian Guide for Autonomous Medication Management, a manual created to be used in the services of the Network of Psychosocial Care of the Unified Health System of Rio Grande do Sul.

Keywords: Psychology. Public policy. Inclusion.
\end{abstract}

\section{Introdução}

O Curso de Psicologia da Universidade da Região da Campanha-URCAMP-Bagé -Brasil busca um processo formativo numa perspectiva científica, reflexiva e ética, de desenvolvimento solidário, sustentável e em defesa da justiça social e dos direitos humanos. O Estágio Curricular compreende atividades teórico-práticas que primam pelos cuidados inclusivos preconizados nas políticas públicas. A reforma psiquiátrica (2002) referencia a substituição da assistência em instituições totais por uma rede de atenção psicossocial de base comunitária; desconstruir e reconstruir em novas bases saberes e práticas em saúde mental; transformar as relações sociais que sustentam a discriminação, a negligência e a violência para pessoas com transtorno mental. Dados de dezembro de 2014 demonstram uma rede com 2209 Centros de Atenção Psicossocial e 899 serviços residenciais em funcionamento ou já habilitados no Brasil. Assim, o CAPS II e a Residência Terapêutica são locais onde ocorrem as práticas dos acadêmicos do 7 o semestre junto aos usuários desses serviços. Desde 2013 diferentes projetos vem sendo construídos pelos acadêmicos e usuários: oficinas de alfabetização e culinária, tarefas voltadas para o incremento da função cognitiva (flexibilidade mental, mudança de contexto, planejamento, memória de trabalho), reconhecimento e utilização de valores monetários, e uso consciente das medicações. Aqui relataremos brevemente o projeto que exemplifica esta prática e que realizou-se no Centro de Atenção Psicossocial - CAPS II, adotando o projeto Construindo autonomia frente à medicação, embasado no GAM-BR (Guia Brasileiro de Gestão Autônoma de Medicação). O GAM é um recurso terapêutico que busca o desenvolvimento de conhecimentos e habilidades nos usuários com transtornos mentais. É um guia para o cuidado compartilhado de psicofármacos que pretende uma comunicação mais direta com o público a que se destina. O projeto partiu de um diagnóstico psicossocial que identificou as demandas da unidade de saúde.

\section{Metodologia}

A organização do estágio envolveu um supervisor acadêmico que deve ser um professor psicólogo da instituição ao qual cabe acompanhar o trabalho dos estagiários, articulando e coordenando o processo ensino-aprendizagem, sugerindo, assinalando atividades e/ou demandas emergentes; estimular a capacidade de ação, criatividade e sensibilidade dos estagiários e avaliar o desempenho dos mesmos frente aos objetivos propostos. O estagiário precisa dispor de, no mínimo, oito horas semanais, divididas em turnos, durante o semestre em curso. O acadêmico deve realizar o diagnóstico da instituição ou comunidade, norteado pelo contexto das práticas psicológicas nas políticas públicas, o que permite a elaboração de projetos de ação adequados às demandas para posterior execução. Foram realizadas atividades lúdicas e artísticas como recortes e colagens, entre estas o manuseio das caixas dos medicamentos utilizados e a administração adequada. 


\section{Procedimentos de Execução}

O primeiro contato dos acadêmicos com a instituição foi através da apresentação e observação de seu funcionamento. Através de uma roda de conversa os usuários contaram suas histórias de vida, há quanto tempo frequentavam o CAPS, seus sofrimentos $\mathrm{e}$ inúmeras dificuldades, permitindo que fossem compreendidas as necessidades e indicações terapêuticas, saltava aos olhos o grau de dependência cotidiana pra orientarem-se, desde o seu diagnóstico, uso da medicação, pessoas com quem podiam contar ou não, potencialidades pessoais, enfim, apenas tinham claro suas limitações. Neste sentido, foi-lhes apresentado o manual GAM-BR como norteador dos trabalhos de grupo e a compreensão dos mesmos sobre a proposta. As atividades artísticas incluíram recortes, colagens, o manuseio das caixas dos medicamentos utilizados na rede pública, a administração adequada e quais as indicações. Identificou-se algumas dificuldades cognitivas como memória e atenção, desfavorecendo a autonomia para a autoadministração, mas principalmente esclarecia a necessidade de mais treinamento. A partir destas observações aplicou-se a "técnica do barbante": as pessoas organizam-se em círculo e um dos participantes, com o carretel do barbante na mão, segura sua ponta, passa para outro integrante falando seu nome e lhe atribuindo uma qualidade e este fará o mesmo com o outro colega, até que todos participem formando uma teia. Despertou para a valorização e integração do grupo, mesmo que alguns não aceitassem participar. Ainda nos primeiros encontros debateu-se a reforma psiquiátrica, os CAPS, residências terapêuticas e centros de convivência, garantindo alguns esclarecimentos e já introduzindo o tema rede de apoio. Realizaram desenhos sobre o que havia sido conversado, expressaram-se de forma livre e improvisaram encenações teatrais em dois grupos: o primeiro expressou de forma artística o seu dia-a-dia, com a administração equivocada de seus medicamentos, enquanto o outro grupo após observar o primeiro representou o que acontece quando a administração é correta, ressaltando os aspectos positivos. Participaram alegremente mostrando-se muito criativos e animados, um dos usuários por sua própria iniciativa tocou gaita de boca e cantou algumas canções.

Ocupando a cidade Trabalhando especificamente memória, atenção e senso percepção realizou-se um passeio em volta da quadra e depois uma na praça próxima a unidade, pedindo para que prestassem atenção em tudo o que vissem durante o passeio. $\mathrm{Na}$ praça, fizeram exercícios de alongamento, descontraíram-se conversando, e no retorno ao CAPS questionou-se o que haviam percebido no passeio. Em outros momentos também foram realizadas atividades com o propósito de trabalhar outras funções como controle inibitório, já que identificou-se dificuldades em controlar impulsos e emoções, interferindo no rendimento do grupo. Utilizouse uma técnica de controle do riso: todos em círculo e um dos integrantes do grupo reproduz uma cena engraçada devendo o restante do grupo manter-se sério, sob pena de ser o próximo a ter que encenar.Em ambas as práticas o grupo mostrou-se interessado e participativo exercitando funções importantes não só para autonomia, mas também para o convivência cotidiana.

Rede de Apoio Para reforçar o tema rede de apoio realizou-se o contorno da mão em uma folha de ofício, cada integrante do grupo colocou o nome de um componente importante da sua rede de apoio em cada dedo, mencionaram pessoas que os auxiliavam nos cuidados com seus medicamentos como os familiares, a enfermeira, o médico, a psicóloga, os colegas do grupo. O trabalho foi então exposto pra debate e discussão.

Campos(1999) ressalta que as ações de saúde mental devem obedecer ao modelo de redes de cuidado de base territorial e atuação transversal com outras políticas específicas voltadas ao estabelecimento de vínculos e acolhimento, favorecendo a conexao em rede.

Guia Brasileiro de Gestão Autônoma de Medicação O GAM-BR também aborda qualidade de vida e autoconhecimento, para enfocar estes temas utilizou-se a técnica do espelho: cada integrante recebe uma caixa com um espelho ao fundo e na sala ao lado, um a um passa pela experiência de ver o há dentro e atribuir qualidades a pessoa que veem, sem comentar com os demais colegas até que todos façam o mesmo. Esta técnica estimulou que os usuários falassem positivamente a seu próprio respeito, o que não é usual. Comentaram sobre qualidade de vida com diversas opiniões, foi interessante porque todos, sem exceção, "gostaram do que viram," atribuindo a si mesmo importantes qualidades e contribuindo para a autoestima do grupo. Parafraseando Mailhiot (1998) a dinâmica de grupo constitui um valioso instrumento educacional que pode ser utilizado para trabalhar tanto a teoria como a prática e considera todos os envolvidos neste processo como sujeitos, desde que as técnicas não se constituam um fim mas um meio para promover a discussão de elementos a serem salientados para o grupo - são ferramentas! Várias questões do GAM-BR foram mediadas por atividadas lúdicas e descontraídas, como através da "dança das cadeiras": coloca-se música para que dancem em torno de cadeiras enfileiradas duas a duas até o número de participantes, em determinado momento retira-se uma cadeira e a música é interrompida, todos tem que procurar sentar e o integrante que sobrou em pé perde o jogo. Transpondo pra o nosso GAM, este integrante respondeu perguntas relacionadas ao cotidiano, compreendendo cuidados pessoais, relacionamentos, saúde, medicamentos e autonomia. Ao final foi aberto um debate sobre as respostas onde todos participaram entusiasmados.

Após o preenchimento final do manual GAM-BR direcionou-se os últimos encontros para refletir sobre os temas abordados, sobre a importância do grupo se manter unido e acolhedor aos novos usuários e colaboradores do serviço. Em clima descontraído, registramos nosso último encontro com festa e fotografias. As fotografias mostram o cenário no qual as atividades diárias, e o contexto sócio-cultural são articulados e vividos. As narrativas visuais através de fotografias devem, portanto constituir-se como forma de diálogo entre os usuários envolvidos no processo. A fotografia traz a síntese do momento vivido. 


\section{Resultados e discussões}

De acordo com a vivência dos acadêmicos, as atividades de estágio propiciaram a gradativa autonomia no manejo da vida diária dos usuários do CAPS II, desenvolvendo paulatina autoestima e socialização. Na concepção que valoriza tanto a teoria como a prática e considera todos os envolvidos neste processo como sujeitos, a execução do projeto contribuiu para formação pessoal e profissional dos acadêmicos e professores, reconhecendo uma nova realidade no fazer da psicologia, baseada no respeito incondicional aos sujeitos de direitos.

\section{Conclusão}

A prática realizada com o guia GAM-BR ressaltou a inserção do psicólogo na área da saúde coletiva. O apoio dos profissionais, a orientação e o desenvolvimento da motivação são indispensáveis para a reabilitação dos usuários. O guia foi roteiro e instrumento de trabalho mas a partir das demandas que surgiram, algumas vezes tornaram-se necessárias outras intervenções complementares para que o grupo se mantivesse interessado e participativo, exercitando funções importantes não só para autonomia, mas também para o convívio social. Este constante ir e vir da prática permitiu ao estagiário de políticas públicas vivenciar realidades diferentes daquelas já conhecidas, possibilitando um processo de transformação pessoal. Nesta concepção considera-se a necessidade de que profissionais da saúde possam entender o desenvolvimento de pessoas a partir de uma ótica diferente dos distúrbios, dificuldades, doença e problemas para a saúde, competências e qualidades. Segundo Delours (1998), os sujeitos deveriam aprender a ser, aprender a fazer, aprender a viver juntos e aprender a conhecer.

\section{Referências}

Brasil, Conselho Nacional de Secretários de Saúde. SUS20anos, 2009, Brasília:CONASS,(online)

Campos, G.W.S.,1999, Equipes de referência e apoio especializado matricial: um ensaio sobre a reorganização do trabalho em saúde. Cien. Saúde Colet., v. 4, n. 2, p. 393-403, 1999.

Campos,RTO et al.2012 Guia de Gestao Autônoma de Medicação, DSC/FCM/UNICAMP; AFLORE; IPUB/UFRJ;DP/UFF;DPP/UFRGS

Conselho Federal de Psicologia, Centro de Referências Técnicas em Psicologia e Políticas Públicas (CREPOP), Publicações, 2013, (online)

Delours, J et al,1999, Educação: um tesouro a descubrir in: Relatório para a UNESCO da Comissão Internacional para a Educação do Século XXI

Jornal do Conselho Federal de Psicologia, 2016, 114,Brasília

Mailhiot, G. B. Dinâmica e Gênese dos grupos. $8^{\text {a }}$ ed. São Paulo: Duas Cidades, 1998.

Neiva, KMC.2010 Intervenção psicossocial: aspectos teóricos, metodológicos e experiências práticas. São Paulo:Vetor.

Piaget, J. 1977 O julgamento moral na criança. São Paulo: Mestre Jou 